\title{
Differential motile response of isolated inner and outer hair cells to stimulation by potassium and calcium ions
}

\author{
D. Dulon *, G. Zajic and J. Schacht \\ Kresge Hearing Research Institute, The University of Michigan, Ann Arbor, Michigan, U.S.A.
}

(Received 15 June 1990; accepted 10 October 1990)

\begin{abstract}
Inner and outer hair cells were mechanically isolated from the guinea pig cochlea and subjected to stimuli known to induce shape changes in outer hair cells. Depolarization by $70 \mathrm{mM} \mathrm{KCl}$ which causes osmotic swelling of outer hair cells also swelled inner hair cells by approximately $8 \%$ of their volume. The application of the calcium ionophore ionomycin which induces cortical contractions and elongation of outer hair cells, did not affect the shape of inner hair cells. Since ionomycin increased free intracellular calcium levels in both inner and outer hair cells, the results demonstrate that inner hair cells do not possess the mechanisms necessary for a contractile response to calcium. Thus, calcium is a specific regulator of outer hair cell motility making this mechanism a likely physiological modulator of a transduction feedback process.
\end{abstract}

Outer hair cells; Inner hair cells; Motility; Potassium depolarization; Calcium

\section{Introduction}

There is strong evidence that inner and outer hair cells play different roles in the mammalian cochlea. Inner hair cells are generally considered the primary transducers while outer hair cells have been ascribed a modulatory role in the transduction process (Dallos, 1985; Neely and Kim, 1986). Differences between inner and outer hair cells range from anatomical specializations such as extensive sub-surface cisternae in outer hair cells (Saito, 1983) to differential electrophysiological responses to acoustic stimulation (Cody and Russell, 1985). Specifically, motile properties are thought to be unique characteristics that enable outer hair cells to modify basilar membrane micromechanics. Such motile responses can be

Correspondence to: Jochen Schacht, Kresge Hearing Research Institute, The University of Michigan, Ann Arbor, MI 48109 0506, U.S.A.

- Permanent address: Laboratoire d'Audiologie Expérimentale, Unité INSERM 229, Université de Bordeaux 11, Hôpital Pellegrin, 33076 Bordeaux, France. elicited by a number of stimuli and via a number of different mechanisms. Fast and possibly frequency-following shape changes can be evoked by electrical stimulation of isolated outer hair cells (Brownell et al., 1985; Ashmore, 1987; Zenner et al., 1987). These fast responses appear to depend upon transmembrane potential since blocking the known ionic conductances of these cells does not interfere with the motility (Santos-Sacchi and Dilger, 1988). Slow shape changes in the millisecondto-second time frame occur with chemical stimulation of outer hair cells, notably with depolarization by potassium and elevation of intracellular free calcium ions. $\mathrm{K}^{+}$-depolarization induces an osmotic swelling of the cells which is accompanied by a shortening independent of calcium and structural proteins (Dulon et al., 1988). In isolated outer hair cells, where the plasma membrane has been destroyed by detergents, calcium will cause an irreversible shortening (Flock et al., 1986; Zenner, 1986). In contrast, a rise of intracellular calcium in intact isolated outer hair cells leads to reversible cortical contractions and cell elongation by a mechanism dependent on calmodulin and structural proteins (Dulon et al., 1990). 
A major question in determining the physiological correlates of such in-vitro responses appears to be whether these phenomena are unique to outer hair cells. It can be argued that a regulatory mechanism of basilar membrane micromechanics should specifically control the motility of outer hair cells. Electrical stimulation has already been shown to affect outer hair cell shape only and not inner hair cells (Brownell et al., 1985). The aim of the present study was to determine whether two different 'slow' stimuli, potassium depolarization and the elevation of intracellular calcium elicit shape changes in both outer and inner hair cells.

\section{Methods}

\section{Hair cell isolation}

Outer hair cells were isolated from the cochlea of pigmented guinea pigs as previously described (Zajic and Schacht, 1987; Dulon et al., 1989), and inner hair cells were obtained by essentially the same procedure. The whole organ of Corti was dissected in Hanks' Balanced Salt Solution (HBSS; buffered to $\mathrm{pH} 7.4$ with $5 \mathrm{mM}$ sodium $N$-2-hydroxyethylpiperazine- $N^{\prime}$-2-ethanesulfonate [HEPES], and adjusted to an osmolality of $300 \pm 1$ mOsm with $\mathrm{NaCl}$ ). Fragments from each turn were then transfered with a microsyringe (\#705, 22-gauge; Hamilton, Reno, NV) into separate 50 $\mu 1$ droplets of HBSS containing $0.5 \mathrm{mg}$ collagenase/ml (type IV from Sigma, St. Louis, MO). After $15 \mathrm{~min}$ of incubation at room temperature $\left(20-22^{\circ} \mathrm{C}\right)$, the strips of the organ of Corti were transfered into $50 \mu \mathrm{l}$ of collagenase-free HBSS on glass slides. The dissociation procedure was completed by gentle flux and efflux of the tissue pieces through the micropipette. After settling for $5 \mathrm{~min}$, adhesion of the cells to the glass was sufficiently strong to prevent them from being dislodged by the addition of experimental solutions. All steps of the isolation procedure were carried out in a humid chamber in order to avoid evaporation and changes in the osmolality of the solutions.

On the average, one guinea pig cochlea yielded approximately 250 viable outer and 20 to 30 inner hair cells. Contrary to outer hair cells, the yield of isolated inner hair cells was higher from the basal part of the cochlea than the apex.

\section{Measurement of intracellular calcium}

Loading of the calcium-sensitive dye and fluorescence measurements were performed as previously described (Dulon et al., 1989, 1990). Hair cells were incubated for $30 \mathrm{~min}$ at room temperature $\left(22-25^{\circ} \mathrm{C}\right.$ ) with $2 \mu \mathrm{M}$ fluo-3/AM (Molecular Probes Inc., Eugene, OR) in HBSS and observed with an inverted microscope (Leitz Fluovert fitted with an epifluorescence system [ArcLamp HBO $100 \mathrm{~W} ; 450-490 \mathrm{~nm}$ band-pass exciter filter, 510 $\mathrm{nm}$ dichroic mirror and $520 \mathrm{~nm}$ harrier filter for excitation and emission, respectively] and a Leitz 160/- NPL FLUOTAR 50/1.00 oil immersion objective). Cell fluorescence was monitored with a Silicon Intensified Target video camera (SIT 66, Dage-MTI Inc., Michigan City, IN) and analyzed with a Quantex QX-7-210 image processing system (Quantex Corp., Sunnyvale, CA). The concentrations of intracellular calcium were calculated (Dulon et al., 1990) according to the equation (Koa et al., 1989) $[\mathrm{Ca} 2+]_{\mathrm{i}}=\mathrm{K}_{\mathrm{d}}(\mathrm{F}-$ $\left.F_{\min }\right) /\left(F_{\max }-F\right) . K_{d}$ is the dissociation constant for the fluo-3/calcium complex; $F$ is the observed fluorescence in arbitrary units of intact fluo-3 loaded cells; $F_{\max }$ (fluorescence maximum) was calculated from the equation $F_{\max }=\left(F_{M n}-F_{b k g}\right) /$ $0.2+F_{b k g} . F_{M n}$ is the fluorescent signal obtained after treatment of the cells with ionomycin (10 $\mu \mathrm{M} ; 60 \mathrm{~s})$ and $\mathrm{MnCl}_{2}(2 \mathrm{mM} ; 3$ to $5 \mathrm{~min}) ; \mathrm{F}_{\mathrm{bkg}}$ is the fluorescent signal obtained after lysis of the cells with $100 \mu \mathrm{g}$ saponin $/ \mathrm{ml} ; 0.2$ is the ratio of the signal of the $\mathrm{Mn}^{2+}$-saturated fluo-3 to that of the $\mathrm{Ca}^{2+}$-saturated dye. $\mathrm{F}_{\text {min }}$ (fluorescence minimum) was calculated from the equation $F_{\min }=$ $\left(F_{\max }-F_{b k g}\right) / 40+F_{b k g}$ where $1 / 40$ is the ratio of the fluorescent signal of metal-free fluo- 3 to the $\mathrm{Ca}^{2+}$ complex.

\section{Application of stimuli}

Ten mM stock solutions of ionomycin (from Calbiochem, La Jolla, CA) were prepared in DMSO. The ionophore was added to the cells to yield a final concentration of $10 \mu \mathrm{M}$ (final concentration of DMSO, $0.1 \%$ ).

For $\left[\mathrm{K}^{+}\right]$-depolarization $(70 \mathrm{mM} \mathrm{KCl}$ final concentration), $50 \mu \mathrm{l}$ of a $140 \mathrm{mM} \mathrm{KCl-HBSS}$ solution $\left(\mathrm{Na}^{+}\right.$replaced by $\mathrm{KCl}$ and osmolality adjusted to $300 \pm 1$ mosm) was gently added with 
a pipette to $50 \mu 1$ of normal HBSS containing the cells.

\section{Measurement of hair cell dimensions}

Cell length was simultaneously monitored on bright field images and analyzed with the Quantex-QX-7-210. The system provided measurements with a resolution of $\pm 0.2 \mu \mathrm{m}$ as tested with calibrated fluorescent microspheres (Polysciences, Warmington, PA). The cell lengths reported are the distance between the cuticular plate and the synaptic ending of the cell. The cell volume was calculated from the two-dimensional video images of the cells by treating these as projections of defined three-dimensional bodies. Outer hair cells were divided into five segments whose diameter and length were individually determined, and volume was calculated assuming a cylinder. Inner hair cells were divided near the neck region into two segments, and volume was calculated assuming a truncated cone for the neck and a sphere for the lower portion of the cell.

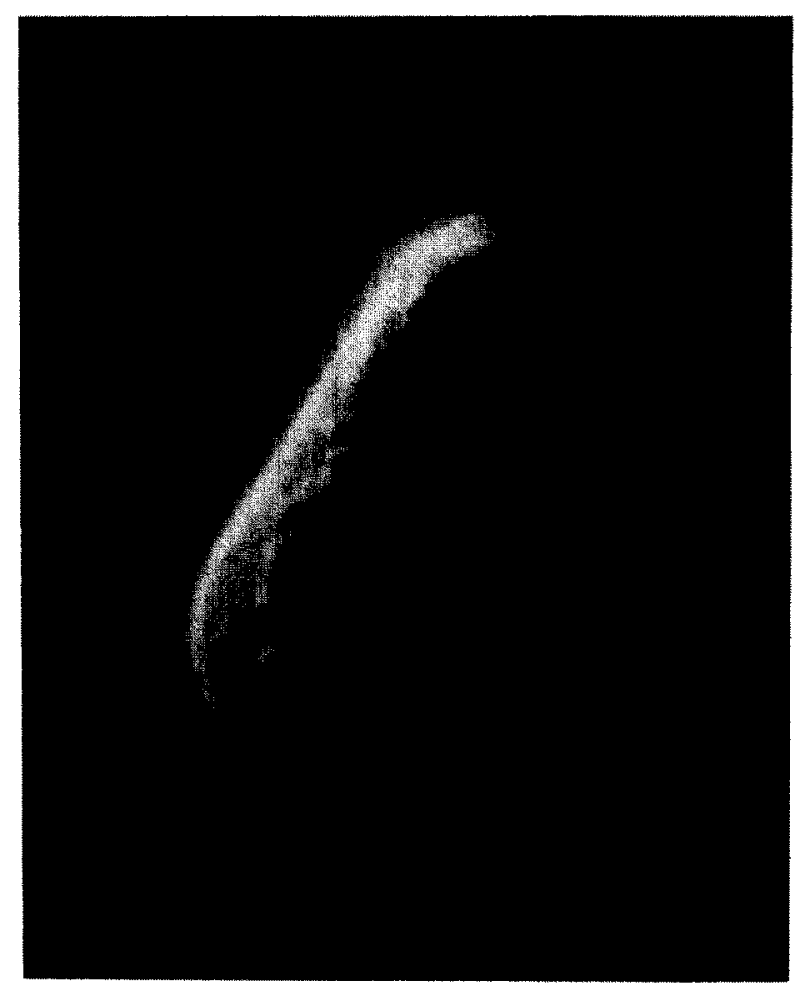

Fig. 1. Isolated inner and outer hair cells from the base of the cochlea. Left: inner hair cell, right: basal outer hair cell. Cells were

isolated and maintained in culture as described in 'Methods'. Calibration bar: $5 \mu \mathrm{m}$.

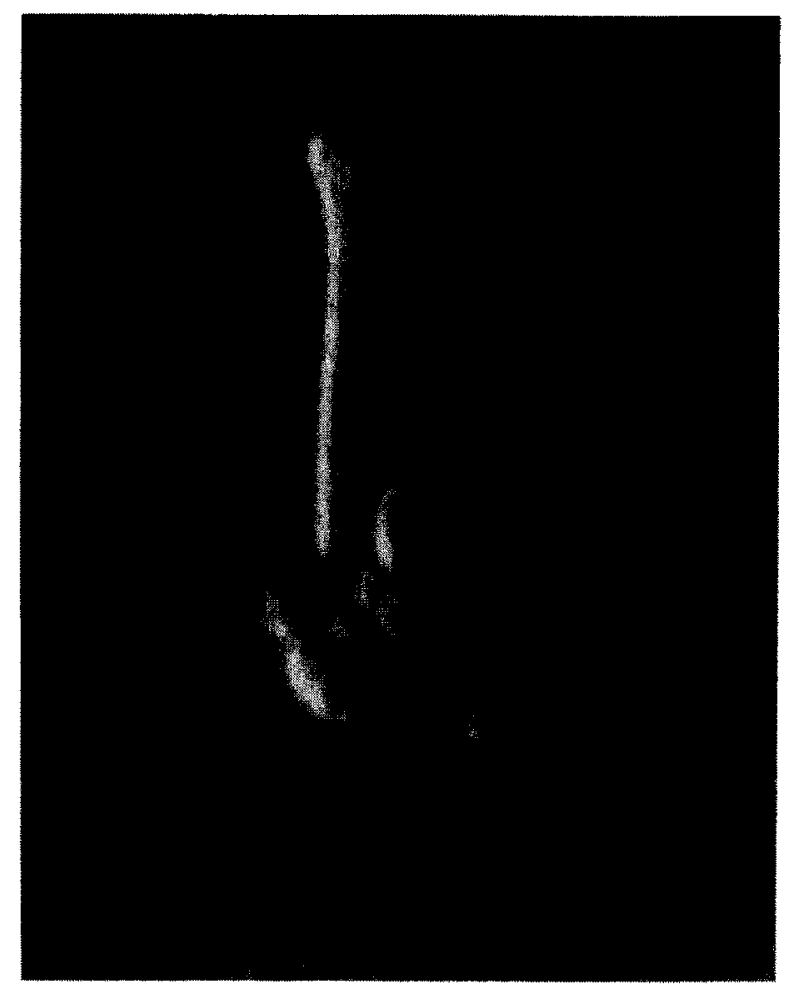

\section{Hair cell isolation}

The dimensions of isolated inner hair cells varied somewhat along the cochlear spiral. The length ranged from 25 to $40 \mu \mathrm{m}$ with apical hair cells being longer, and their diameter, measured across the nucleus, from 15 to $20 \mu \mathrm{m}$. These variations were small compared to the length of outer hair cells which varies three- to four-fold from approximately $20 \mu \mathrm{m}$ in the base to over 70 $\mu \mathrm{m}$ in the apex of the guinea pig cochlea.

Inner hair cells can be distinguished from basal outer hair cells of the same length by several features (Fig. 1). Inner hair cells are flask- or pear-shaped while outer hair cells are cylindrical. Outer hair cells will also often have numerous nerve terminals attached to their base while this is not seen in inner hair cells. The diameter of isolated inner hair cells is almost twice as large as the corresponding diameter of outer hair cells ( 8 to 10 $\mu \mathrm{m})$ whether they are basal or apical. The apex of 
inner hair cells tapers to a neck region which is smaller than that of outer hair cells. This region is regularly tilted to one side probably corresponding to the angular anchoring of inner hair cells in the cuticular plate in vivo. The neck widens at the cuticular plate which looks concave in contrast to the usually flat-appearing cuticular region of an outer hair cell. The length of the stereocilia is another distinguishing characteristic. The tallest stereocilia of inner hair cells are longer than those of basal outer hair cells. Our measurements show inner hair cell stereocilia to average $6.5 \mu \mathrm{m}(6.45$ $+0.71 \mu \mathrm{m} ; N=7$ ) while those of basal outer hair cells do not exceed $5 \mu \mathrm{m}(4.03 \pm 1.15 \mu \mathrm{m} ; N=9)$. Only at more apical levels of the cochlea do outer hair cell stereocilia approach the same length and exceed those of inner hair cells ( $\mathrm{Lim}, 1980$ ). Another distinguishing feature is the size and position of the nucleus. The nucleus of outer hair cells $(8.01 \pm 0.35 ; N=12)$ is smaller than that of inner hair cells $(9.71 \pm 0.56 ; N=6) ;$-it is located at the extreme base of the cell in outer but higher in inner hair cells. By these criteria, a previously published 'inner' hair cell (Yamashita et al., 1990) most likely represents a short outer hair cell.

Both outer and inner hair cells maintain their distinctive shape after isolation indicative of a rigid lateral cell wall. Swelling does occur in some cells after isolation, probably as a result of exposure to mechanical or chemical stress. It is usually confined to the synaptic regions of either cell species. In isolated inner hair cells, the swollen region shows a clear cytoplasm, with intracellular organelles remaining more apically. If swelling occurs at the base of isolated outer hair cells they may resemble inner hair cells in shape. The base of the outer hair cells will, however, mostly maintain a structured cytoplasm.

While outer hair cells could be maintained in culture for several hours, inner hair cells appeared less stable and the useful lifespan of a preparation was approximately $60 \mathrm{~min}$. After this time, inner hair cells began to deteriorate showing increased Brownian motion in the cytoplasm and excessive swelling.

\section{Effects of $\mathrm{K}^{+}$-depolarization}

Viable isolated inner hair cells, as previously described for outer hair cells, were capable of
TABLE I

EFFECTS OF $\mathrm{K}^{+}$-DEPOLARIZATION ON ISOLATED INNER HAIR CELLS

\begin{tabular}{lrrrr}
\hline & Before $^{+}$ & After K $^{+}$ & क Change $^{\mathrm{l}}$ \\
\hline Calcium $(\mathrm{nM})$ & $182 \pm 88$ & $346 \pm 189$ & $+91 \pm 52^{2}$ \\
Length $(\mu \mathrm{m})$ & $37.5 \pm 9.3$ & $37.7 \pm 9.4$ & $+0.4 \pm 1.8^{3}$ \\
Diameter $(\mu \mathrm{m})$ & $19.1 \pm 3.5$ & $20.0 \pm 4.0$ & $+4.4 \pm 3.7^{4}$ \\
Volume $(\mathrm{pL})$ & $3.7 \pm 0.5$ & $4.0 \pm 0.5$ & $+7.7 \pm 2.6^{2}$ \\
\hline
\end{tabular}

Cells were isolated and treated as described in 'Methods' and exposed to the stimulus for $1 \mathrm{~min}$. Results for calcium and for cell dimensions are from separate experiments. Diameter was measured at the widest area across the nucleus. Numbers are means $\pm \mathrm{SD} ; N=20$ (calcium) and 7 (dimensions). ${ }^{1}$ Percent change calculated from individual cells before and after treatment; ${ }^{2} P<0.01$ by paired $t$-test on individual cells before and after treatment; ${ }^{3}$ not significant; ${ }^{4} P=0.03$ by paired $t$-test on individual cells before and after treatment.

hydrolyzing the membrane permeant form of the calcium sensitive probe fluo-3/AM to its fluorescent derivative compound fluo- 3 and of accumulating it in their cytoplasm. In the absence of stimulation, the concentration of intracellular free calcium of inner hair cells was $182 \pm 88 \mathrm{nM}(\mathrm{Ta}-$ ble I). This calcium concentration is of the same magnitude as found in isolated outer hair cells (Dulon et al., 1989, 1990). The external application of $70 \mathrm{mM} \mathrm{KCl}$ increased intracellular calcium in 20 of 20 inner hair cells (Table I) similar to the increase reported in outer hair cells (Dulon et al., 1989).

TABLE II

EFFECTS OF CALCIUM IONOPHORE ON INNER HAIR CELLS

\begin{tabular}{llll}
\hline & $\begin{array}{l}\text { Before } \\
(\mu \mathrm{m})\end{array}$ & $\begin{array}{l}\text { After } \\
(\mu \mathrm{m})\end{array}$ & $\begin{array}{l}\text { Change }^{\mathrm{I}} \\
(\%)\end{array}$ \\
\hline Calcium & 2 & 2 & $+84 \pm 129^{3}$ \\
Length $(\mu \mathrm{m})$ & $31.5 \pm 4.7$ & $31.3 \pm 4.8$ & $-0.6 \pm 0.8^{4}$ \\
Diameter $(\mu \mathrm{m})$ & $17.8 \pm 1.8$ & $17.9 \pm 1.9$ & $+0.7 \pm 1.2^{4}$ \\
\hline
\end{tabular}

Cells were isolated and treated as described in 'Methods' and exposed to the stimulus for $1 \mathrm{~min}$. Results for calcium and for cell dimensions are from separate experiments. Diameter was measured at the widest area near the base of the cell. Numbers are means $\pm S D ; N=19$ (calcium), and 12 (dimensions). ${ }^{1}$ Percent change calculated from individual cells before and after treatment; ${ }^{2}$ Calcium determined in arbitrary units; ${ }^{3} P=0.015$ by paired t-test on individual cells before and after treatment; ${ }^{4}$ Dimensions of individual cells did not change significantly. 
Potassium-depolarization also caused inner hair cells to swell consistently with 7 out of 7 cells responding (Table II). As determined from individual cells before and after treatment, cell volume increased by $7.7 \%$ due to an increase in cell diameter by $4.4 \% \pm 3.7$. Cell length essentially remained unaffected $( \pm 0.4 \% \pm 1.8)$. This is analogous to the well-documented behavior of isolated outer hair cells to swell in response to depolarization with $\mathrm{KCl}$ by 5 to $10 \%$ (Zenner 1986; Dulon et al., 1988).

\section{Effects of ionomycin}

The external application of the calcium ionophore ionomycin to inner hair cells raised their intracellular free calcium concentrations (Fig. 2) within seconds. The increase in calcium fluorescence averaged $91 \%$ and was observed in 16 of 19 cells (Table II). Their shape, however, remained unaffected by the addition of ionophore: there were no significant changes in length or diameter and, consequently, in volume. Under identical conditions, outer hair cells consistently elongated in agreement with our previous results (Dulon et al., 1990). Seven out of 7 outer hair cells responded with a $50 \% \pm 33$ increase in calcium fluoresence $(P<0.01$ by paired $t$-test) and another 9 out of 10 outer hair cells responded with a $5.2 \% \pm$ 3.6 increase in their length (from $69.6 \pm 8.7$ to $73.0 \pm 7.9 \mu \mathrm{m} ; P<0.01$ by paired $t$-test)

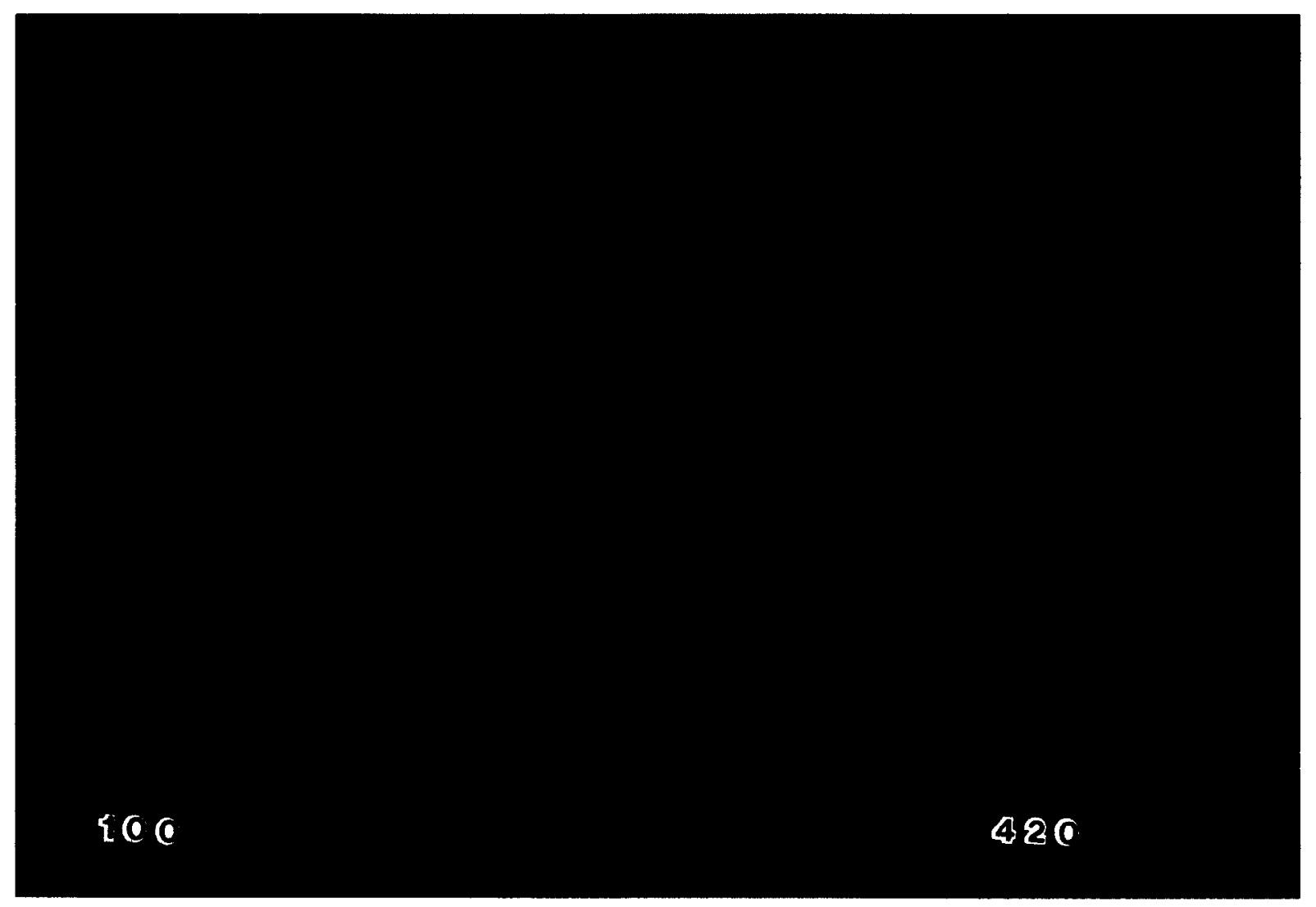

Fig. 2. Imaging of intracellular free calcium in an isolated inner hair cell. Left: cell before stimulus; right: 60 sec after stimulus. The cell was isolated and treated with ionomycin as described in 'Methods'. Levels of intracellular free calcium ion are displayed in pseudocolors. Calibration ramp: concentration of free calcium ion [nM]. 


\section{Discussion}

Isolated inner and outer hair cells demonstrate a differential response to chemical stimuli that induce slow shape changes. Potassium-induced depolarization equally affects the shape of both cell types while the response to elevated intracellular free calcium is unique to outer hair cells. These are compatible results since potassium and calcium operate via different mechanisms.

We speculate that the depolarization-induced shape change in inner hair cells is the result of a passive osmotic swelling independent of contractile proteins as has been demonstrated for outer hair cells (Zenner et al., 1985; Dulon et al., 1988, 1989). This osmotic phenomenon seems to be based on chloride influx since it could be abolished in outer hair cells when potassium gluconate was substituted for potassium chloride (Ulfendahl, 1988). However, while both cell shortening and increase in diameter is associated with this swelling in outer hair cells, inner hair cells mainly change their diameter. This contrasting behavior may stem from differences in the rigidity of the lateral wall of the two cell types and the elongated tubular shape of outer hair cells. Furthermore, we have proposed that the depolarization-induced rise of intracellular calcium in outer hair cells is mediated by voltage-gated calcium channels (Dulon et al., 1989). Although more pharmacological information is needed, it is likely that calcium entry in inner hair cells similarly occurs via voltage-gated channels.

Ionomycin provides a ionophoric action for calcium at the plasma membrane. Inner hair cells did not respond with a shape change to this stimulus. This is in contrast to outer hair cells in which ionomycin triggers calcium entry followed by a calmodulin-mediated circumferential contraction leading to cell elongation (Dulon et al., 1990). The first step of the ionomycin-induced sequence, namely calcium entry, is clearly evident in inner hair cells. Therefore, the absence of a shape change suggests that inner hair cells do not possess $a^{2}$ calcium-dependent contractile apparatus.

In conclusion, this analysis of inner and outer hair cell motility strongly reinforces intracellular calcium as a specific regulator of outer hair cell motility. Thus, this mechanism is a most likely physiological modulator of a transduction feedback mechanism.

\section{Acknowledgment}

This work was supported by Program Project grant DC-00078 from the National Institutes of Health.

\section{References}

Ashmore, J.F. (1987) A fast motile response in guinea-pig outer hair cells: The cellular basis of the cochlear amplifier. J. Physiol. 388, 323-347.

Cody, A.R, and Russel, I.J. (1985) Outer hair cells in the mammalian cochlea and noise-induced hearing loss. Nature $315,662-665$.

Brownell, W.E., Bader, C.R., Bertrand, D. and de Ribaupierre, $Y$. (1985) Evoked mechanical responses of isolated cochlear outer hair cells. Science 227, 194-196.

Dallos, P. (1985) Response characteristics of mammalian cochlear hair cells. J. Neurosci. 5, 1591-1608

Dulon, D., Aran J-M, and Schacht, J. (1988) Potassium-depolarization induces motility in outer hair cells by an osmotic mechanism. Hear. Res. 32, 123-130.

Dulon, D., Zajic, G., Aran, J-M, and Schacht, J. (1989) Aminoglycoside antibiotics impair calcium entry but not viability and motility in isolated outer hair cells. J. Neurosci. Res. $24,338-346$.

Dulon D., Zajic, G. and Schacht, J. (1990) Increasing intracellular free calcium induces circumferential contractions in isolated outer hair cells. J. Neurosci. 10, 1388-1397.

Flock $\AA$., Flock B. and Ulfendahl, M. (1986) Mechanisms of movement in outer hair cells and a possible structural basis. Arch. Otorhinolaryngol. 243, 83-90.

Kao, J.P.Y., Harootunian A.T. and Tsien, R.Y. (1989) Photochemically generated zytosolic calcium pulses and their detection by fluo-3. J. Biol. Chem. 264, 8179-8184.

Lim, D.J. (1980) Cochlear anatomy related to cochlear micromechanics. A review. J. Acoust. Soc. Am. 67, 1686-1695.

Neely S.T. and Kim D.O. (1986) A model for active elements in cochlear biomechanics. J. Acoust. Soc. Am. 79, 14721480 .

Saito, K. (1983) Fine structure of the sensory epithelium of guinea pig organ of Corti subsurface cisternae and lamellar bodies in the outer hair cells. Cell Tissue Res. 220, 787-795.

Santos-Sacchi J. and Dilger, J.P. (1988) Whole cell currents and mechanical responses of isolated outer hair cells. Hear. Res. 35, 143-150.

Ulfendahl M. (1988) Volume and length changes in outer hair cells of the guinea pig after potassium-induced shortening. Arch. Otorhinolaryngol. 245, 237-243.

Yamashita, T., Amano, H., Harada, N., Su, Z.L., Kumazawa, T., Tsunoda, Y. and Tashiro, Y. (1990) Calcium distribu- 
tion and mobilization during depolarization in single cochlear hair cells. Acta Otolaryngol. 109, 256-262.

Zajic, G. and Schacht, J. (1987) Comparison of isolated outer hair cells from five mammalian species. Hear. Res. 26, 249-256.
Zenner, H.P. (1986) Motile responses in outer hair cells. Hear. Res. 22, 83-90.

Zenner, H.P., Zimmermann U. and Gitter A.H. (1987) Fast motility of isolated mammalian auditory sensory cells. Biochem. Bionhys. Res. Commun. 149, 304-308. 